\title{
Kompatibilitas Vegetatif Fusarium oxysporum dari Beberapa Tanaman Inang
}

\author{
Sri Hartati $1^{*}$, Ummu Salamah Rustiani ${ }^{2}$, Lindung Tri Puspasari ${ }^{1}$ dan Wawan Kurniawan ${ }^{1}$ \\ ${ }^{1}$ Departemen Hama dan Penyakit Tumbuhan, Fakultas Pertanian, Universitas Padjadjaran \\ Jl. Raya Bandung-Sumedang KM 21 Jatinangor 40600 \\ ${ }^{2}$ Pusat Karantina Tumbuhan dan Keamanan Hayati Nabati, Badan Karantina Pertanian Kantor \\ Pusat Kementerian Pertanian Gedung E Lt. 5, Jl. Harsono RM No. 3 Ragunan Jakarta \\ *Alamat korespondensi: s.hartati@unpad.ac.id
}

\section{ABSTRACT \\ Vegetatif compatibility of Fusarium oxysporum on various hosts}

Many strains or race of Fusarium oxysporum can be grouped based on compatibility reproduction from a variety of different strains called Vegetative Compatibility Group (VCG). This study was aimed to determine how the grouping of several isolates of $F$. oxysporum and grouping of several hosts of the fungus by vegetative compatibility group. Fusarium oxysporum isolated from chickpea plants that showed symptoms of fusarium wilt. The isolates of $F$. oxysporum of chili and tomatoes obtained from the culture collections of Mycology Laboratory of IPB. Stages of vegetative compatibility testing assayed through recovery of nit mutants, the identification of phenotype of nit mutant, and complementation test. There are 29 mutants isolated from the isolates of $F$. oxysporum. Nit1 mutant was obtained from all isolates of beans, tomatoes and peppers. NitM and Nit3 mutant isolates were obtained from chickpea 4 and chili sequentially. Two VCG and one single self compatibility (SSC) were assayed from isolates of $F$. oxysporum based on complementation testing.

Keywords: Beans, Fusarium wilt, Nit mutant, SSC, VCG

\begin{abstract}
ABSTRAK
Jamur Fusarium oxysporum memiliki banyak forma spesialis dan ras. Jamur ini dapat dikelompokkan berdasarkan kompatibilitas reproduksi dari berbagai strain yang berbeda disebut dengan vegetative compatibility group (VCG). Penelitian ini bertujuan untuk mengetahui cara pengelompokkan $F$. oxysporum dan pengelompokkan jamur tersebut dari beberapa inang berdasarkan kelompok kompatibilitas vegetatifnya. Isolasi $F$. oxysporum dilakukan dari tanaman kacang panjang yang menunjukkan gejala layu fusarium. Isolat $F$. oxysporum dari cabai dan tomat berasal dari koleksi Laboratorium Mikologi IPB. Tahapan pengujian kompatibilitas vegetatif melalui pembiakan nit mutan, identifikasi fenotipe nit mutan, dan pengujian komplementasi. Isolasi mutan F. oxysporum didapatkan 29 mutan. Mutan nit1 didapatkan dari semua isolat yang diperoleh dari semua inang yang berbeda yaitu kacang panjang, tomat dan cabai. Mutan nitM hanya didapatkan dari isolat kacang panjang 4 dan mutan nit3 hanya didapatkan dari isolat cabai. Berdasarkan uji komplementasi $F$. oxysporum yang diuji terdiri dari dua VCG dan satu single self compatibility (SSC).
\end{abstract}

Kata Kunci: Kacang panjang, Layu fusarium, Nit mutant, SSC, VCG

\section{PENDAHULUAN}

Fusarium oxysporum merupakan patogen tanaman terbawa tanah (soilborne) yang tersebar di seluruh dunia. Jamur ini menyebabkan penyakit layu dan mempunyai kisaran tanaman inang yang luas. Spesies Fusarium diklasifikasikan kedalam forma spesialis yang didasarkan pada tanaman inang 
yang diserangnya. Beberapa forma spesialis lebih lanjut dibagi lagi kedalam ras-ras berdasarkan virulensi pada beberapa kultivar inang yang berbeda. Vegetative Compatibility Group (VCG) adalah cara pengelompokkan jamur yang didasarkan pada pertukaran genetik antara isolat yang berbedabeda yang dipasang-pasangkan, atau didasarkan pada kompatibilitas reproduksi dari berbagai strain yang berbeda (Davis, 2005). Teknik ini juga dapat digunakan untuk membedakan antara dua strain atau lebih dengan lebih akurat. Menurut Puhalla (1985) teknik VCG digunakan berdasarkan kemampuan miselium jamur untuk anastomosis dari genetik yang berhubungan melalui pembentukan heterokarion.

Pembentukan heterokarion ditunjukkan oleh sepasang mutan yang tidak dapat mereduksi nitrat disebut nit mutan, yang dapat diperoleh dengan menumbuhkan isolat pada media $\mathrm{KClO}_{3}$ (de Carvalho \& Mendes-Costa, 2011). Teknik ini telah berhasil mendeterminasi fusarium yang diketahui sebagai penyebab layu pada tanaman cumin (Cuminum cyminum L.) di Rajasthan, India (Deshwal \& Kumari, 2012).

Aplikasi VCG telah dilakukan terhadap isolat-isolat $F$. oxysporum dimana isolat dengan VCG sama akan berada pada klone yang sama meskipun berasal dari daerah geografis yang berbeda (Leslie, 1990). Menurut Abo et al. (2005) tingkat keragaman VCG $F$. oxysporum termasuk tinggi. Hal ini ditunjukkan dari hasil penelitian Primo et al. (2001) bahwa dari 160 sampel isolat $F$. oxysporum f.sp. radicis-lycopersici ditemukan lima VCG dan empat VCG ditemukan dalam sampel $F$. oxysporum f. sp. cubense di satu negara (Koenig et al., 1997).

Hingga kini, penggolongan spesies $F$. oxysporum kedalam subspesies masih menemui kendala. Hal ini dikarenakan $F$. oxysporum yang diisolasi dari tanaman inang yang berbeda ternyata mempunyai keragaman genetik yang berbeda pula. Oleh karena itu, dilakukan penggolongan subspesies berdasarkan VCG.

Pengetahuan tentang subspesies penyebab penyakit yang spesifik tentu saja akan lebih membantu para fitopatologis dalam menentukan strategi pengendalian terhadap spesies yang dimaksud. Tujuan dari penelitian ini adalah untuk mengetahui cara pengelompokkan $F$. oxysporum dan pengelompokkan jamur tersebut dari beberapa inang berdasarkan kelompok kompatibilitas vegetatifnya.

\section{BAHAN DAN METODE}

Penelitian dilakukan di Laboratorium Mikologi Departemen Proteksi Tanaman, Institut Pertanian Bogor. Waktu pelaksanaan penelitian pada bulan Maret sampai Juli 2012.

\section{Isolasi dan Identifikasi Jamur $F$. oxysporum}

Isolasi $F$. oxysporum dilakukan pada tanaman kacang panjang yang menunjukkan gejala layu fusarium. Isolasi dilakukan dengan memotong pangkal batang antara daerah yang sehat dan sakit, selanjutnya dicuci dengan air steril. Potongan pangkal batang tersebut didisinfeksi dengan merendam dalam larutan $\mathrm{NaOCl} 1 \%$ selama 2 menit dan dibilas dengan akuades steril sebanyak tiga kali, selanjutnya dikeringkan dengan meletakkannya dalam cawan petri yang telah dialasi kertas saring steril. Potongan pangkal batang yang telah steril diletakkan pada media Potato Dextrose Agar (PDA) dan diinkubasi pada suhu kamar. Jamur Fusarium yang tumbuh diisolasi dan dimurnikan pada media PDA.

Identifikasi $F$. oxysporum dilakukan dengan menggunakan media Carnation Leaf Agar (CLA) yaitu media agar air ditambah dengan potongan daun carnation steril. Potongan isolat Fusarium umur 6-7 hari berukuran $1 \mathrm{~cm}$ diletakkan di tengah pada media CLA, selanjutnya tiga potongan daun carnation steril diletakkan pada pinggir di sekeliling isolat Fusarium tersebut. Identifikasi dengan menggunakan media CLA ini digunakan untuk melihat sporulasi Fusarium hasil isolasi. Selain dengan melihat sporulasi, identifikasi juga dilakukan dengan mengamati karakteristik koloni isolat Fusarium yang didapatkan.

\section{Pengujian Kompatibilitas Vegetatif $F$. oxysporum}

Isolat $F$. oxysporum yang diperoleh dari hasil isolasi dan isolat yang telah ada $(F$. oxysporum dari cabai dan tomat koleksi Laboratorium Mikologi IPB) selanjutnya diuji kompatibiltas vegetatifnya untuk mengetahui pengelompokkan VCG. Metode yang digunakan berdasarkan Cove (1976) yang telah dimodifikasi oleh Puhalla (1985) dan Correl et al. (1987). Tahapan yang dilakukan dalam pengujian kompatibilitas vegetatif adalah pembiakan nit mutan (recovery of nit mutant), identifikasi fenotipe nit mutan, dan pengujian komplementasi (complementation test). 


\section{Pembiakan nit Mutan (Recovery of nit Mutant)}

Isolat $F$. oxysporum pada media PDA yang telah diinkubasi 5-7 hari dipindahkan masingmasing pada media minimal (MM) ditambah klorat $\left(\mathrm{KClO}_{3}\right)$ 1,5\%. Media minimal terdiri dari media dasar $+\mathrm{NaNO}_{3}(2 \mathrm{~g} / \mathrm{l})$. Komposisi media dasar adalah sucrose $30 \mathrm{~g}, \mathrm{KH}_{2} \mathrm{PO}_{4} 1 \mathrm{~g}, \mathrm{MgSO}_{4} .7 \mathrm{H}_{2} \mathrm{O} 0,5 \mathrm{~g}, \mathrm{KCl}$

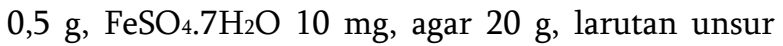
mikro (Trace Element Solution) 0,2 ml, akuades $1000 \mathrm{ml}$. Larutan unsur mikro terdiri dari akuades $95 \mathrm{ml}$, citric acid $5 \mathrm{~g}, \quad \mathrm{ZnSO}_{4} .7 \mathrm{H}_{2} \mathrm{O} 5 \mathrm{~g}$, $\mathrm{Fe}\left(\mathrm{NH}_{4}\right)_{2}\left(\mathrm{SO}_{4}\right) 2.6 \mathrm{H}_{2} \mathrm{O} 1 \mathrm{~g}, \mathrm{CuSO}_{4} .5 \mathrm{H}_{2} \mathrm{O} \quad 0,25$ g, $\mathrm{KClO}_{3} 1,5 \%, \mathrm{MnSO}_{4} . \mathrm{H}_{2} \mathrm{O} 50 \mathrm{mg}, \mathrm{H}_{3} \mathrm{BO}_{4} 50 \mathrm{mg}$. Ukuran koloni $F$. oxysporum yang diambil adalah 2 $\mathrm{mm}^{2}$, masing-masing isolat diambil sebanyak 12 potong dan diinkubasi sampai 15 hari pada suhu ruang. Pengamatan dilakukan setiap hari. Koloni yang miseliumnya tumbuh sangat tipis dan tumbuh lebih cepat diantara miselium lainnya adalah mutan. Mutan yang didapatkan dipindahkan pada medium minimal dan dipelihara untuk pengujian selanjutnya. Persentase pertumbuhan mutan dihitung dengan rumus:

Pertumbuhan mutan (\%)

$=\underline{\sum \text { mutan yang tumbuh }} \times 100 \%$

$\Sigma$ potongan isolat

\section{Identifikasi Fenotipe nit Mutan}

Mutan yang didapat dari tahapan recovery nit mutant, selanjutnya diidentifikasi fenotipenya. Tahapan identifikasi dilakukan dengan menumbuhkan masing-masing nit mutan yang diperoleh pada media minimal (medium dasar + $\mathrm{NaNO}_{3} 2 \mathrm{~g} / \mathrm{l}$ ), media nitrit (media dasar $+\mathrm{NaNO}_{2} 0,5$ $\mathrm{g} / \mathrm{l}$ ) dan media hypoxanthin (media dasar + hypoxanthin $0,2 \mathrm{~g} / \mathrm{l}$ ). Identifikasi nit mutan berdasarkan fenotipe nit mutan ini didasarkan pada kemampuannya menggunakan beberapa sumber nitrogen (Tabel 1).

Tabel 1. Identifikasi fenotipe mutan dan pertumbuhannya pada berbagai media.

\begin{tabular}{lccc}
\hline \multicolumn{1}{r}{ Mutan } & Nitrat & Nitrit & Hypoxanthin \\
\hline Wild type & + & + & + \\
nit1 & - & + & + \\
nit3 & - & - & + \\
NitM & - & + & - \\
\hline
\end{tabular}

Keterangan: $+=$ miselium tumbuh tebal, $-=$ miselium tumbuh tipis. Sumber: Leslie (1990)

Jumlah potongan mutan yang ditumbuhkan sesuai dengan jumlah mutan yang diperoleh dari media $\mathrm{MM}+$ klorat pada masing-masing isolat $F$. oxysporum dan masing-masing diulang 2 kali. Pengamatan dilakukan terhadap fenotipe mutan yang tumbuh berdasarkan Tabel 1. Persentase fenotipe mutan yang tumbuh dihitung dengan rumus:

Fenotipe mutan (\%)

$=\underline{\sum \text { nit } \text { mutan setiap fenotipe } \times 100 \%}$

$\Sigma$ nit mutan yang tumbuh

\section{Pengujian Komplementasi (Complementation test)}

Media yang digunakan untuk pengujian komplementasi adalah media MM (media Nitrat). Nit mutan yang didapat dari tahapan identifikasi fenotipe selanjutnya dipasang-pasangkan yaitu antara nit1 dan NitM dengan berbagai kombinasi sesuai dengan isolat yang diperoleh. Pasangan isolatisolat tersebut diinkubasi pada suhu ruang selama 67 hari.

Pengamatan dilakukan terhadap terjadinya hifa jamur yang membentuk garis tipis atau tumbuhnya koloni yang lebih tebal diantara isolat yang dipasangkan. Penebalan koloni tersebut menunjukkan terjadinya heterokariosis antara isolat jamur yang vegetatifnya kompatibel berdasarkan metode Cove (1976) yang telah dimodifikasi oleh Puhalla (1985) dan Correl et al. (1987). Vegetatif yang kompatibel ditunjukkan dengan adanya hifa yang bersatu dan membentuk garis tebal diantara mutan nit1 dan nitM yang dipasangkan. Sebaliknya, vegetatif yang tidak kompatibel hifanya tidak bersatu dan tidak terbentuk garis tebal diantara nit1 dan nitM yang dipasangkan.

Isolat-isolat yang vegetatifnya kompatibel satu sama lain dikelompokkan dalam VCG yang sama. Pemberian nama kelompok VCG yang ditemukan untuk sementara bedasarkan abjad secara berurutan. Apabila ada isolat yang tidak kompatibel dengan isolat yang lainnya dan tidak termasuk VCG manapun maka isolat tersebut merupakan single self compatibility (SSC) yaitu isolat yang hanya kompatibel secara tunggal.

\section{HASIL DAN PEMBAHASAN}

\section{Isolat Jamur $F$. oxysporum}

Hasil isolasi jamur $F$. oxysporum dari tanaman kacang panjang bergejala layu didapatkan tiga isolat $F$. oxysporum yaitu KP1 (1), KP2 (2) dan KP3 (3). Hasil tersebut berdasarkan identifikasi melalui karakteristik sporulasi pada media CLA dan karakteristik koloni pada media PDA. Sementara itu, tiga isolat lainnya yaitu satu isolat kacang panjang 
KP4 (4), satu isolat tomat T1 (6) dan satu isolat cabai C1 (7) merupakan isolat koleksi Laboratorium Mikologi IPB. Karakteristik koloni F. oxysporum pada media CLA disajikan pada Gambar 1.

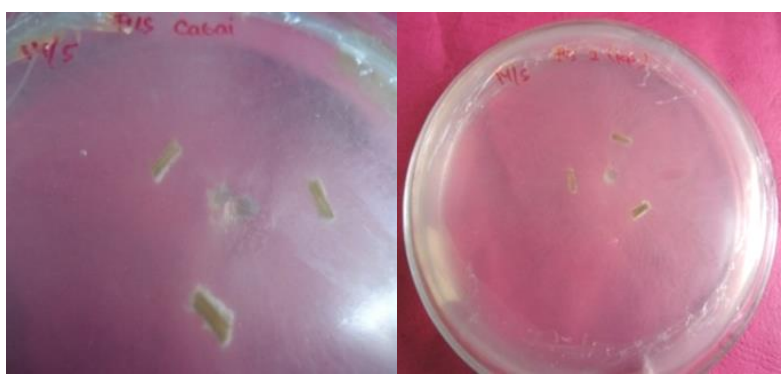

Gambar 1. Koloni isolat F. oxysporum pada media CLA.
Ciri-ciri $F$. oxysporum pada media PDA memiliki koloni mula-mula berwarna putih kemudian berubah menjadi ungu. Warna koloni ini berbeda dengan warna koloni Fusarium solani yaitu berwarna putih agak krem sampai kecoklatan. Jamur F. oxysporum menghasilkan makrokonidia dan mikrokonidia. Makrokonidia biasanya berukuran panjang 25-35 $\mu$ dan lebar 3-5 $\mu$, bagian dorsal melengkung, berbentuk sabit dengan 3-5 septa, dinding tipis dan meruncing ke ujung. F. oxysporum menghasilkan mikrokonidia yang berlimpah, dengan ukuran 5-12 x 3-5 $\mu$, berbentuk oval sampai elips (Smith, 2007). Koloni masing-masing isolat $F$. oxysporum dari inang yang berbeda pada media PDA disajikan pada Gambar 2.

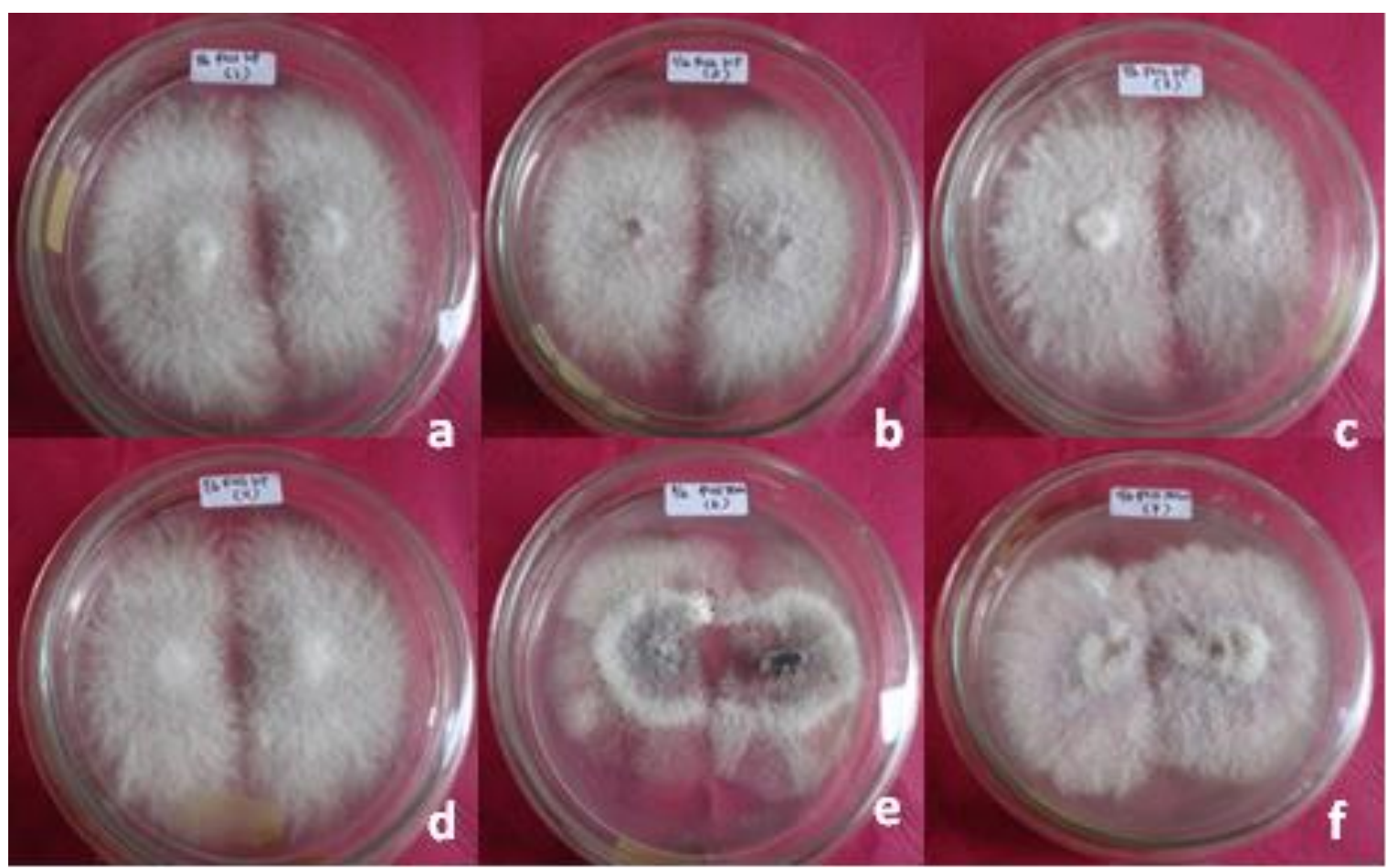

Gambar 2. Koloni F. oxysporum pada media PDA. (a) Isolat kacang panjang 1(1). (b) Isolat kacang panjang 2 (2). (c) Isolat kacang panjang 3 (3). (d) Isolat kacang panjang 4 (4). (e) Isolat tomat (6). (f) Isolat cabai (7).

\section{Kompatibilitas Vegetatif $F$. oxysporum Pembiakan nit Mutan (Recovery of nit Mutant)}

Hasil isolasi mutan $F$. oxysporum dengan menggunakan medium minimal + klorat $\left(\mathrm{KClO}_{3}\right)$ 1,5\% didapatkan 29 mutan, dengan rincian disajikan pada Tabel 2. Berdasarkan hasil pengujian isolat pada media klorat diketahui bahwa isolat $F$. oxysporum yang berasal dari tomat ( $F$. oxysporum f.sp. lycopersic1) (isolat 6) membentuk mutan yang paling banyak yaitu sebesar $50 \%$. Isolat $F$. oxysporum yang berasal dari kacang panjang [KP2 (2)], kacang panjang [KP4 (4)] dan cabai [C1 (7)] membentuk jumlah mutan yang sama yaitu sebesar $41,67 \%$. Sementara itu, isolat dari kacang panjang [KP1 (1)] dan kacang panjang [KP3 (3)] membentuk mutan hanya 33,33\% (Tabel 3).

Mutan $F$. oxysporum adalah isolat yang tumbuh dengan cepat pada media klorat. Koloni tipe liar pada media MM ditambah klorat, akan tumbuh sangat terbatas dan tipis (Gambar 3). Menurut Widodo et al. (2008) koloni mutan akan tumbuh membentuk sektor-sektor yang resisten terhadap klorat dan berkembang dengan cepat dibandingkan koloni yang terbatas (tipe liarnya) setelah 4-15 hari. 
Tabel 2. Mutan F. oxysporum pada medium klorat dari beberapa isolat.

\begin{tabular}{llc}
\hline \multicolumn{1}{c}{ Asal isolat/nama isolat } & \multicolumn{1}{c}{ Mutan dengan kode isolat } & Persentase pertumbuhan mutan (\%) \\
\hline Kacang panjang/KP1 (1) & $1.8 ; 1.9 ; 1.11 ; 1.12$ & 33,33 \\
Kacang panjang/KP2 (2) & $2.1 ; 2.2 ; 2.3 ; 2.4 ; 2.5$ & 41,67 \\
Kacang panjang/KP3 (3) & $3.1 ; 3.2 ; 3.3 ; 3.5$ & 33,33 \\
Kacang panjang/KP4 (4) & $4.7 ; 4.8 ; 4.9 ; 4.11 ; 4.12$ & 41,67 \\
Tomat/T1 (6) & $6.7 ; 6.8 ; 6.9 ; 6.10 ; 6.11 ; 6.12$ & 50,00 \\
Cabai/C1 (7) & $7.1 ; 7.2 ; 7.3 ; 7.4 ; 7.5$ & 41,67 \\
\hline
\end{tabular}

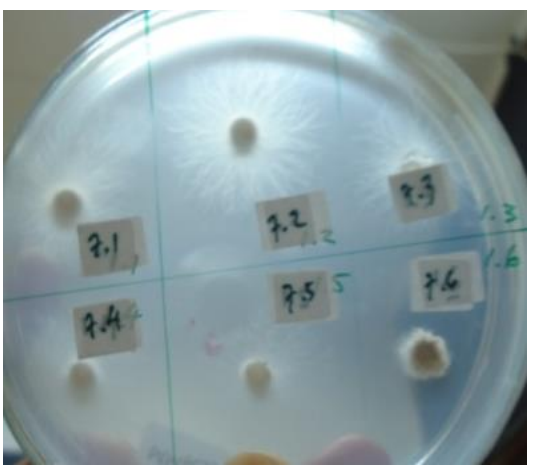

Gambar 3. Koloni mutan (pertumbuhan cepat) dan bukan mutan (pertumbuhan lambat) $F$. oxysporum pada media klorat $\left(\mathrm{KClO}_{3}\right)$ $1,5 \%$.
"Nit mutant auxotroph" dapat tumbuh pada media minimal seperti tipe liarnya tetapi koloninya sangat tipis. Menurut Puhalla (1985) mutan F. oxysporum yang ditumbuhkan pada medium klorat merupakan mutan yang resisten terhadap klorat dan tidak mampu mereduksi nitrat. Demikian juga menurut de Carvalho \& Mendes-Costa (2011) nit mutan adalah mutan yang tidak mampu memanfaatkan nitrat sebagai sumber nitrogen dan tahan terhadap klorat, yang merupakan analog racun dari nitrat. Beberapa pertumbuhan mutan dari hasil pengujian di media klorat disajikan pada Gambar 4.

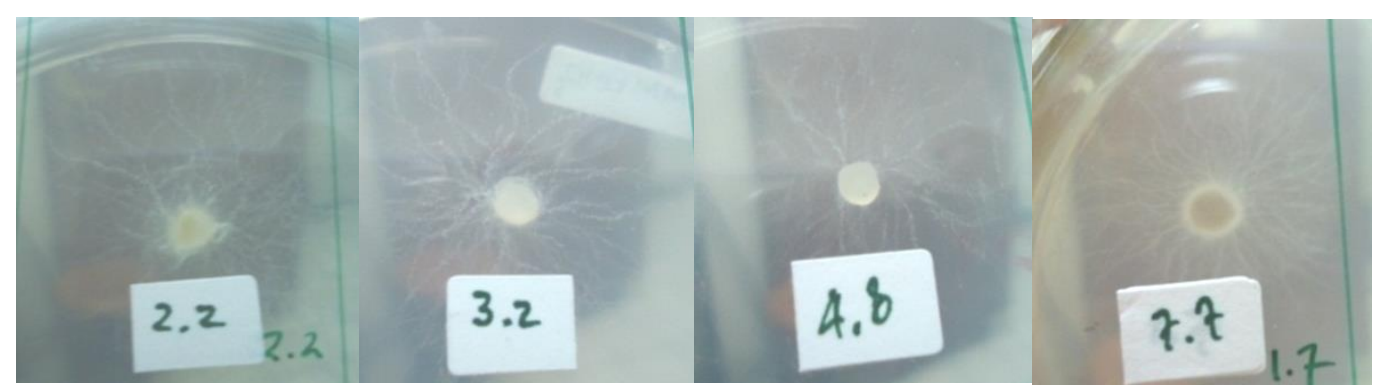

Gambar 4. Beberapa koloni mutan F. oxysporum pada medium klorat.

\section{Identifikasi Fenotipe nit Mutan}

Hasil identifikasi nit mutan menunjukkan bahwa mutan nit1 didapatkan dari semua isolat yang diperoleh dari semua inang yang berbeda yaitu kacang panjang, tomat dan cabai. Mutan nit1 dari semua inang paling banyak diperoleh dari tomat (isolat 6) yaitu sebesar $100 \%$, hasil ini sesuai dengan hasil nit mutan yang terbentuk pada media klorat dimana nit mutan isolat $F$. oxysporum terbanyak terbentuk pada isolat asal tomat. Isolat yang berasal dari kacang panjang membentuk nit1 sebesar
$55,56 \%$, dan yang paling sedikit membentuk nit1 adalah isolat yang berasal dari cabai yaitu hanya $20 \%$. Diantara isolat-isolat yang didapatkan dari tiga inang yang diuji hanya isolat dari kacang panjang 4 yang membentuk nitM dan hanya isolat dari cabai yang membentuk nit3 yaitu masing-masing hanya sebesar 20\% (Tabel 3). Pada inang kacang panjang, diketahui bahwa kacang panjang 4 (KP4) membentuk nit1 paling banyak yaitu sebesar $80 \%$ dan yang paling sedikit membentuk nit1 adalah isolat dari KP1 (Tabel 3). 
Tabel 3. Fenotipe dan persentase fenotipe nit mutan $F$. oxysporum dari beberapa inang.

\begin{tabular}{llccc}
\hline Asal isolat/Nama isolat & \multicolumn{1}{c}{ Kode isolat } & $\begin{array}{c}\text { Fenotipe } \\
\text { nit mutan }\end{array}$ & $\begin{array}{c}\text { Persentase fenotipe } \\
(\%)\end{array}$ & $\begin{array}{c}\text { Persentase fenotipe (\%) } \\
\text { (Total) }\end{array}$ \\
\hline Kacang panjang/KP1 (1) & 1.8 & nit1 & 25 & \multirow{2}{*}{55,56} \\
\hline Kacang panjang/KP2 (2) & $2.3 ; 2.4 ; 2.5$ & nit1 & 60 \\
\hline Kacang panjang/KP3 (3) & $3.3 ; 3.5$ & nit1 & 50 & 5,56 \\
\cline { 1 - 4 } Kacang panjang/KP4 (4) & $4.8 ; 4.9 ; 4.11 ; 4.12$ & nit1 & 80 & 100 \\
\cline { 2 - 5 } Tomat/T1 (6) & 4.7 & nitM & 20 & 20 \\
\hline \multirow{2}{*}{ Cabai/C1 (7) } & $6.7 ; 6.8 ; 6.9 ; 6.10 ;$ & nit1 & 100 & 20 \\
\hline
\end{tabular}

Berdasarkan hasil identifikasi fenotipe diketahui bahwa inang yang sama dapat mempunyai jumlah nit1 yang berbeda-beda. Isolat nit1 adalah isolat mutan yang tidak dapat memanfaatkan nitrat, tetapi dapat memanfaatkan nitrit dan hypoxanthin. Oleh karena itu, isolat ini mampu tumbuh seperti tipe liarnya pada media minimal nitrit dan hypoxanthin, tetapi tumbuh sangat tipis pada media minimal nitrat. Berbeda dengan nit1, isolat nit3 tumbuh seperti tipe liarnya hanya pada media minimal hypoxanthin tetapi tumbuh sangat tipis pada media minimal nitrat dan nitrit. Sementara itu, NitM tumbuh seperti tipe liarnya hanya pada media minimal nitrat, tetapi tumbuh sangat tipis pada media minimal nitrat dan hypoxanthin. Hasil tersebut sesuai dengan yang dijelaskan oleh Leslie (1990). Perbandingan fenotipe nit1, nit3, nitM dan tipe liar disajikan pada Gambar 5.

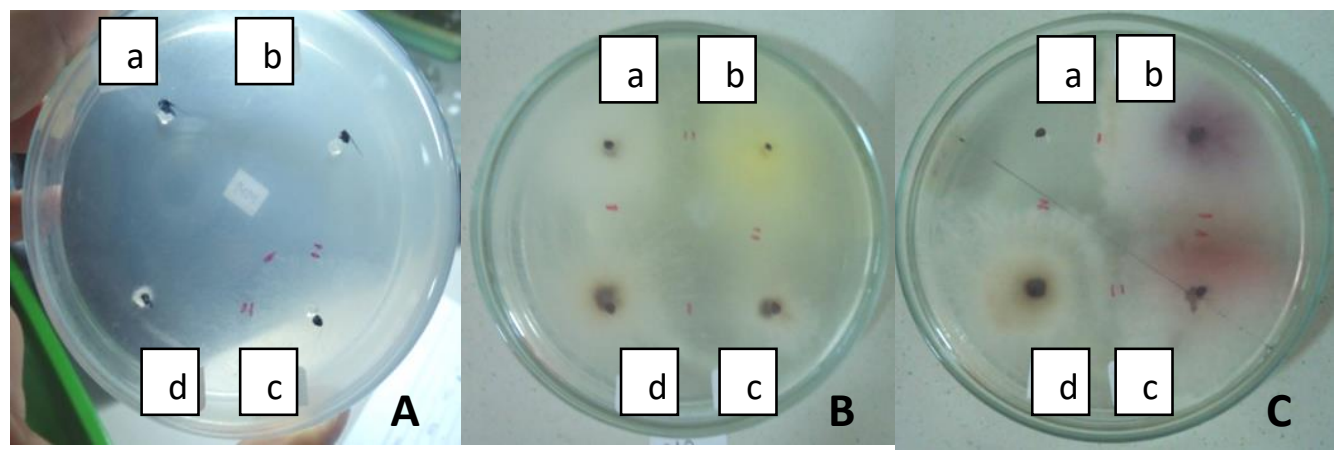

Gambar 5. Fenotipe nit mutan F. oxysporum pada. (A) Media minimal (nitrat). (B) Medium nitrit. (C) Medium hypoxanthin (a. nitM, b. nit1, c. nit3, d. tipe liar).

\section{Pengujian Komplementasi (Complementation Test)}

Hasil pengujian komplementasi menunjukkan bahwa ada beberapa nit1 yang menunjukkan adanya penyatuan miselium dengan nitM, yaitu nit1 yang berasal dari isolat kacang panjang 2, kacang panjang 3 dan isolat tomat (Tabel 4; Gambar 6). Hasil ini menunjukkan bahwa isolatisolat tersebut kompatibel vegetatif. Akan tetapi, penyatuan miselium antara nit1 dan nitM tidak diikuti dengan penebalan miselium. Hal ini diduga disebabkan karena biakan murni $F$. oxysporum tidak diperoleh dari spora tunggal.
Selain terjadinya penyatuan miselium, sebagian isolat yang lain yaitu isolat kacang panjang 1 dan cabai menunjukkan adanya pembatas yaitu berupa zona bening antara miselium nit1 dan nitM (Tabel 4; Gambar 6). Hal ini menunjukkan bahwa antara nit1 dan nitM pada isolat tersebut tidak kompatibel vegetatif. Pengujian antara nit1 isolat kacang panjang 4 dengan nitM yang juga didapat dari isolat kacang panjang 4, juga menunjukkan tidak adanya penyatuan miselium dan terbentuk zona pembatas atau tidak kompatibel vegetatif (Tabel 4; Gambar 6). 
Tabel 4. Komplementasi isolat $F$. oxysporum dari beberapa inang.

\begin{tabular}{|c|c|c|c|}
\hline Kode isolat nitM/asal & Kode isolat (nit1) & Asal isolat & Keterangan \\
\hline \multirow{6}{*}{ 4.7/Kacang panjang } & $2.4 ; 2.3 ; 2.5$ & Kacang panjang & \multirow{3}{*}{$\begin{array}{l}\text { Miselium menyatu tetapi tidak } \\
\text { terjadi penebalan }\end{array}$} \\
\hline & $3.3 ; 3.5$ & Kacang panjang & \\
\hline & $6.7 ; 6.8 ; 6.9 ; 6.10 ; 6.11 ; 6.12$ & Tomat & \\
\hline & 1.8 & Kacang panjang & \multirow{3}{*}{$\begin{array}{l}\text { Miselium tidak menyatu } \\
\text { terdapat zona bening (pembatas) }\end{array}$} \\
\hline & $4.8 ; 4.9 ; 4.11 ; 4.12$ & Kacang panjang & \\
\hline & 7.4 & Cabai & \\
\hline
\end{tabular}

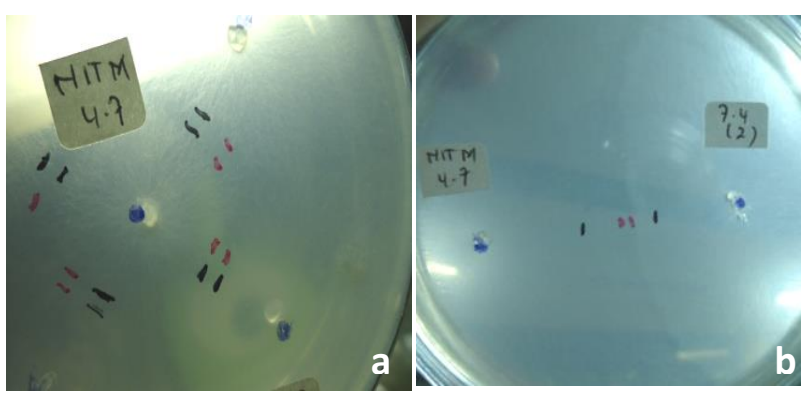

Gambar 6. Vegetative Compatibility Groups (VCG) Isolat $F$. oxysporum. (a) Terjadi penyatuan miselium dan (b) terbentuk zona bening.

Mutan nit3 tidak digunakan dalam pengujian kompatibilitas, dalam pengujian ini hanya digunakan nit1 dan nitM. Menurut Widodo et al. (2008), nit3 merupakan isolat mutan yang tidak stabil sehingga sewaktu-waktu bisa berubah menjadi tipe liarnya.

Berdasarkan uji komplementasi diketahui bahwa isolat $F$. oxysporum yang diuji terdiri dari dua VCG dan satu SSC. Dua VCG tersebut adalah VCGa untuk isolat dari kacang panjang 2, kacang panjang 3 dan tomat, VCGb untuk isolat dari kacang panjang 1 dan cabai, sedangkan SSC untuk isolat dari kacang panjang 4.

Menurut Puhalla (1985), VCG berkaitan erat dengan forma spesialis. Hubungan ini dapat dijelaskan melalui model evolusi jamur. Satu forma spesialis diperoleh dari satu spesies inang yang spesifik. Strain jamur yang kompatibel vegetatif satu sama lain sering digambarkan sebagai anggota kelompok kompatibilitas vegetatif yang sama atau VCG dan yang inkompatibel vegetatif disebut sebagai kelompok kompatibilitas vegetatif yang berbeda (Puhalla, 1985). Akan tetapi, terdapat isolat yang tidak kompatibel dengan isolat lainnya tetapi hanya kompatibel dengan isolat yang sama, isolat yang demikian disebut dengan single self compatibility (SSC). Menurut Widodo (2008) apabila ada isolat yang tidak kompatibel dengan isolat yang lainnya dan tidak termasuk VCG manapun maka isolat tersebut merupakan SSC yaitu isolat yang hanya kompatibel secara tunggal.

Komplementasi adalah interaksi kerja sama gen-gen mutan dalam suatu mutasi rangkap sehingga dihasilkan fenotipe yang lebih mendekati tipe liarnya dibandingkan dengan yang mungkin dihasilkan oleh gen mutan itu sendiri-sendiri. Pembentukan heterokarion ditunjukkan oleh komplementasi antara mutan-mutan yang tidak dapat mereduksi nitrat (nit mutants). Komplementasi antara nit mutan berbeda ditunjukkan oleh perkembangan miselia di zona kontak antara dua koloni mutan (heterokarion) sehingga dua isolat termasuk dalam kelompok kompatibilitas vegetatif yang sama (Puhalla, 1985).

\section{SIMPULAN}

Analisis VCG efektif digunakan dalam penggolongan grup isolat jamur. Grup VCG yang didapat dari penelitian ini didasarkan pada adanya penyatuan miselium antara mutan nit1 dan nitM yang disebut sebagai kompatibel vegetatif. Grup non kompatibel vegetatif ditunjukkan dengan adanya pembatas berupa zona bening. Berdasarkan kelompok kompatibilitas vegetatifnya $F$. oxysporum yang diuji dikelompokkan dalam dua VCG yang mencakup isolat dari kacang panjang, tomat dan cabai dan satu SSC isolat dari kacang panjang.

\section{DAFTAR PUSTAKA}

Abo, K, KK Klein, V Edel-Hermann, N Gautheron, D Traore, and C Steinberg. 2005. High genetic diversity among strains of Fusarium oxysporum f. sp. vasinfectum from cotton in Ivory Coast. Phytopathology. 95:1391-1396.

Correll, JC, CJR Klittich, and JF Leslie. 1987. Nitrate non-utilizing mutants of Fusarium oxysporum and their use in vegetative 
compatibility test. Phytopathology. 77:1640-1646.

Cove, D.J. 1976. Chlorate toxicity in Aspergillus nidulans: the selection and characterization of chlorate resistant mutants. Heredity. 36(2):191-203.

Davis, R. 2005. Fusarium Wilt (Panama Disease) of Banana. Pest Advisory Leaflet. No. 42. Plant Protection Service, Secretariat of the Pacific Community.

de Carvalho, CR, and MC Mendes-Costa. 2011. Vegetative compatibility and heterokaryon formation between different isolates of Colletotrichum lindemuthianum by using the nit mutant system. Brazilian Journal of Microbiology. 42:346-353.

Deshwal, RK and N Kumari. 2012. Regional variation in genetic structure and pathogenecity of Fusarium oxysporum f. sp. cumini isolated from Cuminum cyminum L. Asian Journal of Biological Sciences. 5(1): 30-38.

Di Primo, P, G Cartia, and T Katan. 2001. Vegetative compatibility and heterokaryon stability in Fusarium oxysporum f. sp. radicis- lycopersici from Italy. Plant Pathology. 50:371-382.

Koenig, RL, RC Ploetz, and HC Kistler. 1997. Fusarium oxysporum f.sp. cubense consists of a small number of divergent and globally distributed clonal lineages. Phytopathology. 87:915-923.

Leslie, JF. 1990. Genetic exchange within sexual and asexual populations of the genus Fusarium. Pp. 37-48 in Fusarium Wilt of Banana (RC Ploetz, ed.). APS Press. St Paul.

Puhalla, JE. 1985. Classification of strain of Fusarium oxysporum on the basis of vegetative compatibility. Canadian Journal of Botany. 63(2):179-183.

Smith, SN. 2007. An overview of ecological and habitat aspects in the genus Fusarium with special emphasis on the soil- borne pathogenic forms. Plant Pathology Bulletin. 16: 97-120.

Widodo, N Kondo, K Kobayashi, and A Ogoshi. 2008. Vegetative compatibility groups within Fusarium oxysporum f. sp. cepae in Hokkaido-Japan. Microbiology. 2(1): 39-43. 